\title{
A emergência das minorias étnicas no Brasil: Agendamento das políticas públicas para comunidades quilombolas
}

\section{Isabelle Picelli \\ Instituto Nacional de Colonização e Reforma Agrária (INCRA)}

Resumo: $O$ presente trabalho tem por objetivo analisar o processo de agenda setting do Artigo 68 das Disposições Transitórias da Constituição Federal de 1988 que estabelece o direito à propriedade das terras ocupadas aos remanescentes de quilombos. A pesquisa realiza um mapeamento do processo do tema das terras quilombolas desde o ressurgimento do movimento negro até a promulgação da Constituição Federal de 1988. Para compreender a mudança de posicionamento do Estado, o Modelo do Equilíbrio Pontuado e a abordagem do Institucionalismo Discursivo foram escolhidos. O process tracing revelou que o movimento negro contemporâneo encampa as demandas de comunidades negras rurais pela titulação de suas terras. As ideias gestadas e transportadas por esse grupo de interesse são de fundamental importância para a justificação do dispositivo que estabelece a propriedade das terras quilombolas. Além do trabalho ideológico, o centenário da Abolição da escravidão representou um focusing event que colocou a questão racial na agenda decisória.

Palavras-chave: Quilombo; Movimento negro contemporâneo; Agenda setting; Equilíbrio Pontuado. 


\title{
The emergency of ethnic minorities in Brazil: Agenda of public policies for quilombolas communities
}

\begin{abstract}
This paper has the goal of analyzing the process of agenda setting of the article 68 in the Transient Constitucional Acts of the Federal Constitution of 1988 which states the right to land ownership for people who reside in remaining areas of 'quilombos'. In order to understand the shift in approach of the State, regarding these groups, the work of analyzing empiric data and theoretic approaches showed that the model o Punctuated Equilibrium and Discursive Institutionalism as the most suitable. Process trancing utilized revealed that the black movement encompasses demands of rural black communities for land ownership. The ideas conceived and disseminated by this interest group are of essential to justify the article that establishes the ownership of quilombola lands. Besides the ideologic efforts devoted by the black movement, the one hundredth anniversary of slavery abolition represented a focusing event which put the race issue in the center of decision making process.
\end{abstract}

Keywords: Quilombo communities; Contemporary black movement; Agenda setting; Punctuated Equilibrium.

\section{La aparición de las minorías étnicas en Brasil: La programación de las políticas públicas para las comunidades quilombolas}

Resúmen: El objetivo de este estudio es analizar el processo de agenda setting del Artículo 68 de las Disposiciones Transitorias de la Constitución Federal de 1988, la que establece el derecho del remanente de los quilombos a la propiedad de las tierras ocupadas. La presente investigación lleva a cabo el relevamiento del proceso que ha tomado el tema de las tierras quilombolas desde el resurgimiento del movimiento negro a la promulgación de la Constitución Federal de 1988. Para entender el cambio en la posición del Estado fueron elegidos la Teoría del Equilibrio Puntuado y el abordaje del Institucionalismo Discursivo. El process tracing ha revelado que el movimiento negro contemporaneo se apropia de las demandas de comunidades negras rurales por la titulación de sus tierras. Las ideas engendradas y llevadas hacia adelante por esse grupo de interés son de importancia fundamental para justificar el dispositivo que establece la propiedad de tierras quilombolas. Además de la labor ideológica, el centenario de la Abolición de la esclavitud ha sido un focusing event que ha puesto el tema racial en la pauta de decisión.

Palabras clave: comunidades afrorrurales; movimiento negro moderno; Agenda setting; Equilibrio Pontuado. 
Nas três últimas décadas o Brasil conheceu um amplo processo de redemocratização que possibilitou a entrada na agenda pública de questões outrora marginais. Disputando espaço com questões tradicionais ao aparelho estatal, grupos de interesse tiveram sucesso em fazer transformar suas demandas em políticas públicas, culminando com uma série de inovações institucionais. Políticas voltadas para minorias étnicas também surgem ou sofrem mudanças estruturais nesse período no Brasil.

A Constituição de 1988 passa a dar visibilidade às comunidades de remanescentes de quilombos, grupos predominantemente negros cujas famílias guardam relação histórica com o processo de escravidão no Brasil. A Carta Magna reconhece aos remanescentes de quilombos, através do Artigo 68 do Ato das Disposições Constitucionais Transitórias (ADCT), a propriedade definitiva sobre as terras que ocupam, devendo o Estado emitir os títulos de propriedade. O Artigo 68 do ADCT abre uma porta para que as comunidades negras rurais sejam consideradas grupos étnicos, com historicidade própria. Antes invisíveis em meio ao campesinato brasileiro, esse dispositivo cria um novo sujeito de direitos, o "remanescente de quilombo". Nos dias atuais a política de regularização fundiária de quilombos tem por fim último garantir o acesso formal à terra, o que possibilita não só a reprodução física e sobrevivência da comunidade mas também sua manutenção enquanto grupo cultural.

Voltando ao tempo da Colônia e do Império brasileiro, pode-se afirmar que o conceito de quilombo vigente à época se referia à "toda habitação de negros fugidos, que passem de cinco, em parte despovoada, ainda que não tenham ranchos levantados e nem se achem pilões nele". Essa definição foi utilizada pelo Conselho Ultramarino em carta ao rei de Portugal no ano de 1740 (Rocha, 2005). Definição semelhante é aquela presente na Lei n. 236, de 20 de agosto de 1847, época de recrudescimento da escravidão no Brasil. Nesse dispositivo consta no artigo 12 que "Reputa-se-há escravo aquilombado, logo que esteja no interior das matas, vizinho ou distante de qualquer estabelecimento, em reunião de dois ou mais com casa ou rancho" (apud ROCHA, 2005: 99). Ambos os conceitos mencionados têm em comum o fato de criminalizarem o fenômeno quilombo (tendo em vista que transgrediam o sistema escravocrata) e tratarem esses grupos como isolados geográfica e culturalmente da sociedade em geral. Essa noção perdurou durante séculos na historiografia brasileira.

O fim do regime escravista, no ano de 1888, não representou o fim da segregação da população negra no Brasil. Não houve qualquer tipo de ação por parte do Estado de reparação ou agregação dos ex-escravos na sociedade mais ampla. Segundo Barcellos (2004), a maioria dos ex-escravos permaneceu trabalhando para seus antigos donos nas plantation, com a novidade da remuneração precária e sob a forte humilhação de sempre. Outros se refugiaram na pequena produção para a subsistência. Gerou-se, assim, um campesinato negro bastante empobrecido, fenômeno que ocorreu em diversos países da América Latina (Almeida, 1998). Nesse contexto de estigmatização e exclusão, a "aquilombagem" (ou seja, a formação de quilombos) foi uma estratégia que perdurou também após a abolição da escravidão.

O termo quilombo não aparecia mais na legislação brasileira desde que a lei abolicionista de 1888 havia revogado as leis que tratavam da escravidão. No 
imaginário social do século XX pairava o entendimento de que o quilombo era um fenômeno do passado, passado que a abolição havia apagado (Leite, 2000).

Depois de um século da ausência do vocábulo quilombo no ordenamento jurídico brasileiro, o fenômeno volta à agenda trazendo como sujeito de direito "os remanescentes de comunidades de quilombos". Um grande volume de questões complexas se apresentava aos legisladores da Constituinte de 1988. Mesmo competindo com questões mais tradicionais na agenda governamental, como por exemplo saúde e trabalho, a questão da inclusão dos remanescentes de quilombos pela via do acesso à terra e da proteção à sua cultura conseguiu chegar à agenda decisional no cenário da redemocratização do país.

Como, então, um fenômeno e um grupo populacional que pareciam estar extintos voltam à realidade presente no texto da Constituição de 1988 em um período de disputa de espaço por diversas questões políticas tradicionais? Como se torna possível o surgimento de uma nova institucionalidade para tratar dos remanescentes de quilombos?

O presente trabalho é síntese de dissertação de mestrado que teve por objetivo compreender quais fatores institucionais e políticos explicam o surgimento de uma política pública de regularização de terras para comunidades quilombolas no Brasil, a partir dos referenciais de agendamento (agenda setting)da Ciência Política.

\section{Abordagem teórica: lógica da comunicação e lógica da atração de atenção}

O Modelo do Equilíbrio Pontuado, de Baumgartner e Jones (Baumgartner e Jones 2009; Jones e Baumgartner, 2012), se mostrou o mais adequado para leitura e explicação do agendamento da política quilombola de regularização fundiária, sobretudo devido à importância dada à construção de imagens políticas (policy images) para a mudança e agendamento de políticas públicas. Recorreu-se também aos achados do Institucionalismo Discursivo (ID) sobre o papel do discurso para mostrar como as ideias exercem influencia causal no mundo político, engendrando a mudança (e a continuidade) das instituições.

Assim como outros modelos que explicam o surgimento de políticas públicas, o Modelo do Equilíbrio Pontuado dá peso importante aos fatores históricos e mudanças externas às instituições que possibilitam o surgimento de novas políticas públicas em um determinado período. No entanto, a mudança institucional dentro dele não é apenas explicada por essas conjunturas críticas ou janelas de oportunidade.

O Modelo do Equilíbrio Pontuado envolve ao menos três elementos importantes na dinâmica que compõe sua explicação da mudança (e da continuidade) institucional: os grupos de interesse tentando promover suas ideias e visões de mundo, em lócus institucionais favoráveis a elas e a busca pela atenção limitada dos líderes governamentais dentro do sistema macropolítico.

Dentro desse modelo, os grupos de interesse disputarão a atenção escassa do sistema macropolítico para suas policy images. Chegar ao macrosistema político - lócus onde acontecem as decisões - atraindo atenção de parlamentares e agentes do executivo, é o objetivo de todo grupo que pretende promover mudanças sociais em algum campo. A maioria das mudanças em políticas públicas ocorrem em períodos de elevada atenção ao problema, segundo Baumgartner e Jones (2009). A política de atração de atenção é ao mesmo tempo produzida pelos grupos mobilizados para a mudança de uma questão, que tentam fazer difundir suas imagens, quanto resultado de processos 
externos aos grupos que criam um ambiente receptivo para novas ideias, como os focusing events, eventos que fazem com que a atenção do macrosistema se volte para um problema (crises, tragédias, datas comemorativas). No âmbito do Modelo do Equilíbrio Pontuado, diferente de outros modelos de agendamento, não basta a ocorrência desses momentos favoráveis para explicar as mudanças institucionais drásticas. Tais mudanças vêm sempre com novas issues definition, ou seja, com novos inputs discursivos, contendo novas ideias acerca de um tema. O cerne de uma nova issue definition é sempre a disputa entre grupos para estabelecer e institucionalizar suas imagens e discursos.

Nesse ponto, uma ponte com o Institucionalismo Discursivo é possível. As imagens que serão levadas à arena decisórias são compostas, sobretudo, por ideias, entendidas aqui como crenças causais (Béland e Cox; 2011). O conflito político envolve disputas em torno da definição de policy images dos problemas e das soluções. Recorrer ao ID foi uma estratégia teórica que buscou dar visibilidade ao conteúdo das ideias e ao processo de transporte dessas à arena decisória (o discurso) pelos atores.

Assim, as ideias tem um papel importante dentro do Equilíbrio Pontuado, tanto para manutenção de monopólios políticos quanto para destruição de hegemonias antigas e inovação institucional. Os grupos de interesses e suas ideias participam tanto na manutenção quanto na alteração institucional.

Tanto o ID e quanto o Modelo do Equilíbrio Pontuado atribuem papel importante às ideias e maior capacidade participativa dos agentes dentro dos subsistemas na manutenção e alteração das instituições do que outras teorias de agendamento. Ao contrário do macrosistema político (que representa as altas esferas de decisão), os subsistemas são compostos de um número limitado de atores e instituições que se especializam e direcionam seus esforços para algumas questões específicas em relação a uma política, como o subsistema que discute política racial.

Em síntese, apresento o surgimento da política de regularização quilombola como uma crise produzida pela ação dos grupos interessados, a partir da produção de novas ideias, visando interromper a inércia institucional. Ao mesmo tempo, reconheço a importância da abertura histórica representada pelo processo de redação da Constituição de 1988, uma janela de oportunidade para a mudança institucional.

A análise empírica privilegiou dados históricos e documentais primários e secundários do período que se inicia com a reorganização do movimento negro no final dos anos 70 e finaliza com a promulgação de Constituição de 1988. Para traçar a trajetória do agendamento do Artigo 68 do ADCT, me valho em especial de documentos oficiais produzidos pelo Movimento Negro Unificado (MNU), de entrevistas com lideranças desse movimento coletadas no âmbito da pesquisa "História do movimento negro no Brasil: constituição de acervo de entrevistas de história oral", desenvolvida no Centro de Pesquisa e Documentação de História Contemporânea do Brasil da Fundação Getúlio Vargas (CPDOC/FGV)1, publicações da chamada "imprensa negra"2 e do acervo "Coleção Constituinte de 1988 " 3 da Biblioteca do Senado Federal, que reúne a produção legislativa da Assembleia Nacional Constituinte e reportagens jornalísticas sobre esse período. 


\section{Inputs promovidos pelo movimento negro contemporâneo e o lugar do quilombo}

O mapeamento do processo revelou que é impossível desvincular o agendamento da política de regularização fundiária quilombola da crise produzida pelo movimento negro contemporâneo. A redemocratização política vivenciada pelo país nos anos 70 e 80 possibilitou a (re)articulação de diversos movimentos sociais. O movimento negro retoma o protesto racial com mais veemência que nos anos de ditadura, com um discurso inovador de denúncia contra a existência do mito da democracia racial e em prol da valorização da história e cultura da população afrodescendente4.

A atuação do movimento negro contemporâneo enquanto grupo de interesse dentro subsistema da questão racial, construindo e difundindo um discurso que pudesse desconstruir a percepção de igualdade material entre os grupos formadores da nação brasileira foi essencial para o agendamento da política pública voltada para populações afrorrurais. O discurso da democracia racial representava um monopólio político sustentado pelas políticas de unidade nacional do regime militar, de vigilância e repressão das ações de afirmação de uma raça negra no Brasil - consideradas separatistas e discriminatórias - e pela não existência de políticas de reconhecimento ou redistribuição que visassem promover a efetiva inclusão dessa população após a abolição da escravidão. É contra esse monopólio político que o movimento negro contemporâneo se insurge, empoderado pelos estudos científicos da década de 1960 que desmistificavam a relação cordial entre escravos e senhores além da apontarem a resultante situação subalterna do negro na sociedade brasileira5.

Sobretudo a partir do final dos anos 70, o movimento negro contemporâneo busca interromper a estabilidade da politica estatal para com a população afro-brasileira. Nesse período, desenvolve-se um discurso que constituiria a base do agendamento de ações consideradas antirracistas no corpo da Carta Magna de 1988.

O chamado movimento negro contemporâneo assume claramente posição contrária à ideia de democracia racial e unidade nacional levadas à cabo pelos sucessivos governos militares. A raça e a identidade racial foram utilizadas como elemento de mobilização e mediação das reivindicações políticas em torno de um projeto comum de nação mais igualitária (Guimarães, 1995). Além da afirmação da existência de uma raça negra, o core discursivo do movimento negro está claramente marcado pela negação do mito da democracia racial.

No core do discurso propagado a essa época por entidades do movimento negro, o quilombo ocupa lugar privilegiado. O movimento negro opera uma mudança na imagem desse fenômeno social e em seu discurso o quilombo passa a ser símbolo da luta antirracista (Arruti, 2006). As menções à Zumbi e à experiência de resistência de Palmares são comuns nos documentos do Movimento Negro Unificado (MNU, 1986; 1988) e nas mídias negras, que se multiplicaram nos anos 70 e 80 (Pereira, 2010)6. O MNU retoma a história da

4 A organização de movimentos negros surge no Brasil ainda nos anos 30 como reação à discriminação e à segregação racial percebidos, mas sem contestar a ideia de que o Brasil era um lugar de privilegiado convívio entre as raças, que vigorou pelo menos até os anos 50 (Domingues, 2007; Maio, 1999).

5 Grande número de obras foram publicadas nos anos 6o e 70, como Brancos e negros e São Paulo (1959), de Roger Bastide e Florestan Fernandes; As metamorfoses do escravo, de Octávio Ianni (1962); Capitalismo e escravidão no Brasil Meridional, de Fernando Henrique Cardoso (1962), entre outros.

6 Encontra-se, por exemplo, referências ao quilombo Palmarino e a Zumbi como símbolos da luta racial no Jornegro, jornal que nasce em 1978 no Rio de Janeiro, e Jornal Nacional do Movimento Negro Unificado. Ambos os periódicos 
resistência absorvida na experiência dos quilombos como a metáfora do Estado livre dentro do Estado escravocrata. $\mathrm{O}$ aquilombamento e as lutas populares escravas passaram a ser vistos como representativos da não passividade do negro diante do sistema escravista. Buscou-se afastar imagens que denotavam a passividade do negro à época ecravagista, como a imagem da Mãe Preta (Domingues, 2007) e a imagem de cordialidade da escravidão, bastantes influenciadas pela obra de Gilberto Freyre, Casa Grande e Senzala (1992).

No ano de sua fundação, 1978, o MNU lança, em 20 de Novembro, um manifesto nacional, que se tornará uma referência importante para a organizações militantes. O manifesto retoma Zumbi como símbolo heroico da luta antirracista e o quilombo como inspiração. A partir dele, o MNU estabelece como data de celebração o dia 20 de novembro (presumível data da morte de Zumbi dos Palmares), a qual foi eleita como Dia Nacional de Consciência Negra. $\mathrm{O}$ dia 20 de novembro é escolhido para difundir a figura de Zumbi enquanto símbolo da resistência à opressão racial.

Além dessa novidade no que se refere à imagem do quilombo, esse fenômeno é tomado pelo movimento negro como símbolo da luta contemporânea por inclusão na sociedade brasileira (Arruti,2006). O quilombo do qual se fala nos anos 80 dentro do movimento negro e suas mídias é basicamente o quilombo de Palmares, sobre o qual se tinha mais conhecimento histórico produzido. Trata-se de uma imagem bastante idílica do fenômeno quilombo, de escravos fugidos, resistindo a partir da luta aberta contra os senhores, vivendo de forma comunal e socializada. Essa imagem foi bastante difundida pelo Quilombismo de Abdias Nascimento (1980;1985)7. Essa imagem idealizada do fenômeno será descontruída posteriormente ao agendamento da política de terras quilombolas pelo boom de trabalhos que recuperarão as trajetórias de diversos quilombos. No período precedente ao agendamento do Artigo 68, no entanto, é a imagem do quilombo palmarino que prevalecerá, sendo ele mesmo o símbolo da luta do MNU.

O trabalho do movimento negro na esfera do discurso coordenativo(Schmidt, 2008) foi se desenhando a partir de uma rede de militância que se expandiu a partir dos anos 80, fomentada pelos encontros promovidos pelo MNU e por encontros regionais como o Encontro de Negros do Norte e Nordeste. Constituiu-se uma grande rede, que apesar da pluralidade de ações (culturais, políticas, assistencialistas) compartilhavam ideias comuns acerca da questão do negro no Brasil, o que chamei de core do discurso. A esfera coordenativa do discurso consiste nos indivíduos e grupos que estão no centro da construção de uma política pública, ou seja, na criação e elaboração de justificativas que provem a importância e conveniência de uma política. É composta pelos atores - como movimentos sociais, organizações da sociedade civil, especialistas, burocratas, agentes políticos eleitos - que buscam construir um consenso acerca das ideias que irão defender.

As ideias gestadas e transportadas pelo movimento negro contemporâneo operaram uma mudança de issue definition, ou seja, uma redefinição da questão racial, com novas ideias e novos atores, que passaram a circular no subsistema

foram acessados no acervo do Centro de Documento e Pesquisa Vergueiro. Disponível em http://www.cpvsp.org.br/acervo.php

7 Abdias Nascimento merece destaque dentre as lideranças do movimento negro tendo em vista sua trajetória dentro dele. Participou das três fases históricas do movimento negro, com atuação na Frente Negra Brasileira (nos anos 30 e 40), no Teatro Experimental Negro - durante o período militar - e participou da construção de entidades militantes nos anos 70 e 80. Foi deputado federal no período de 1983 a 1986, sendo o primeiro parlamentar que dedicou se mandato às questões raciais, escreveu vários livros e participou do processo de internacionalização da luta do movimento negro, estabelecendo relações com grupos negros dos Estados Unidos, África e Europa (Domingues, 2007; Abreu, 2001; Almada, 2009; Nascimento, 1982). 
racial e tentar atrair atenção dos líderes políticos. Essa redefinição colocou em xeque a ideia historicamente difundida de harmonia entre as raças no Brasil.

Nos termos de Scherer-Warren (2006), o movimento negro contemporâneo toma forma de rede de movimento social nos anos 80. Uma rede de movimento social é o resultado do movimento articulatório dos diversos níveis de atuação da sociedade civil. Entendo que o movimento negro contemporâneo se constituirá em rede de movimento social agregando associações locais esportivas, culturais, de estudo, política, de pesquisa, redes regionais que se articularam através de encontros e o MNU - que pretendia ter abrangência nacional - que conseguiu construir valores e ideias compartilhados na esfera do discurso coordenativo. Sobretudo a partir de meados dos anos 80, como aponto mais a frente, essa rede intensificará sua atuação na esfera comunicativa, tendo em vista a aproximação do Centenário da Abolição da escravidão e a Constituinte de 1988.

\section{A Constituinte de 1987 e 1988: Ideias encontram uma janela de oportunidade}

A chegada desse novo input à arena decisória se dá em virtude da atuação de empreendedores políticos que carregaram as ideias gestadas pelo movimento negro para uma arena decisória de grande amplitude, a Assembleia Nacional Constituinte (ANC), na qual diversas questões competiam por espaço. Parlamentares como Benedita da Silva, Carlos Alberto Caó e José Carlos Sabóia foram os mais importantes empreendedores da redefinição da questão racial que o movimento negro tentava implacar, segundo análise feita dos anais da ANC. São esses parlamentares os que mais promovem o core do discurso do movimento negro e a pauta de reivindicações entregue por esse grupo à ANC.

As atas das reuniões da Subcomissão Temática de Negros, Populações Índigenas, Pessoas Deficientes e Minorias 8 revelam a atuação central da deputada Benedita como a maior empreendedora política da questão do negro dentro do ANC. Dentro dessa subcomissão, Benedita atua na apresentação e legitimação das ideias para os outros constituintes. Atuou com um canal de recepção de propostas de diversos grupos e defesa de medidas que garantissem uma verdadeira igualdade entre negros e não-negros. Relata-se nas atas que a subcomissão, por meio de Benedita, recepcionou formalmente as propostas encaminhadas pelo MNU, oriundas da Convenção "O Negro e a Constituinte", de 1986, mas também de grupos negros que, individualmente, encaminharam sugestões de redações de propostas. A participação do deputado Caó também foi de defesa das proposições de interesse do movimento negro. Apesar de não ser titular ou suplente da Subcomissão de Minorias, Caó comparece às audiências dessa subcomissão que tratam da questão do negro, é autor da proposta de criminalização do racismo e defensor da tese da necessidade de ações compensatórias para a efetiva inclusão da população negra.

Na confluência de fatores que levou esse input para a agenda decisória está também o centenário da Abolição da Escravidão. O ano de 1988 será marcado por uma série de eventos de celebração ou questionamento do processo de Abolição da escravidão no Brasil. Esses atos se dão em vários espaços da esfera pública, criando um clima de debate sobre a questão racial no país. 
Levantamento feito por Maggie e equipe (1994) mapeou cerca de 1.700 eventos comemorativos da Abolição no país, sejam eles para "criticar", "repensar", "comemorar" ou "negar" o centenário.

Segundo os vários entrevistados por Alberti e Pereira (2007), o ano de 1988 foi um marco na história do movimento negro contemporâneo no Brasil. $\mathrm{Na}$ tentativa de atrair atenção do macrosistema político, o movimento negro aproveita o centenário da Abolição para a propagação de policy images favoráveis à quebra do monopólio da democracia racial bem como para denunciar que a Abolição ainda era um processo incompleto. É preciso lembrar que em maio - mês da assinatura da Lei Áurea e no qual a maior parte dos eventos se concentra - de 1988 ainda travavam-se disputas dentro da ANC em torno do agendamento das demandas do movimento negro. Nesse ano, o Presidente da República anuncia a criação da Fundação Cultural Palmares, que tinha por objetivo a defesa dos interesses da população negra. Pode-se dizer, portanto, que o centenário da Abolição representa um momento em que a arena decisória prestou alguma atenção à questão do negro no Brasil, mesmo em um momento em que sua atenção estava bastante dividida entre diversos problemas e demandas que se apresentavam à ANC.

Além de considerar o centenário da Abolição como uma janela de oportunidade para o agendamento de políticas defendidas pelo movimento negro, em que maior atenção é dada à situação dessa população e que é manejada por esse grupo de interesse, a própria redação da Constituição de 1988, da forma como foi feita, representa um momento de abertura da estrutura institucional, que proporcionou possibilidades de ruptura. A predominância, no início dos trabalhos da ANC, de uma organização fortemente descentralizada, com subcomissões e comissões temáticas fazendo os estudos iniciais, ouvindo a sociedade e votando, a ausência de um projeto base, constituíram-se em fatores favoráveis à introdução no texto de dispositivos particularistas. Para tal, bastou que esses contassem com o apoio substancial de algum grupo de pressão ou bancada parlamentar e não ferissem os interesses da maioria congressual (Couto e Arantes,2002).

Reconheço aqui o papel importante que a abertura política que a redação do texto Constitucional de 1988 representou para o agendamento de questões do movimento negro. No entanto, a referência a essa conjuntura crítica ou janela de oportunidade seria insuficiente para explicar como e por que se dão algumas mudanças de posicionamento do Estado para com a população negra, em particular com as comunidades negras rurais, reconhecendo-lhes existência legal dentro do sistema jurídico e a propriedade de suas terras. O mapeamento histórico da atuação do movimento negro permite visualizar como a mudança é operada quando esses momentos críticos ocorrem. As ideias foram utilizadas desde os anos 70 e com mais força no anos 80 como armas, no sentido de Blyth (2001), desafiando os arranjos existentes. No âmbito do Modelo do Equilíbrio Pontuado (Baumgartner e Jones, 2009) as mudanças de posicionamento do Estado não são explicadas apenas pelos momentos favoráveis para ruptura. Tais mudanças vêm sempre acompanhadas de novas issues definition, ou seja, de novos inputs ideológicos.

Nem todas as demandas do movimento negro foram para a Carta Magna apesar da grande visibilidade que o tema obteve nos anos de 1987 e 1988 e do momento crítico representado pelo processo de redação da Constituição. A análise das atas da Subcomissão Temática de Negros, Populações Índigenas, Pessoas Deficientes e Minorias, da Comissão de Ordem Social (para a qual o anteprojeto da Subcomissão foi enviado) e da Comissão de Sistematização da 
ANC revela que as demandas por reconhecimento não tiveram grandes pontos de veto, diferentemente das pautas que clamavam por redistribuição, como as políticas compensatórias e afirmativas. Essas últimas sofreram grande oposição ainda na Subcomissão Temática, primeira etapa do processo legislativo Constituinte. Medidas que garantissem tratamento diferenciado, como reserva de vagas em órgãos públicos e empresas, visando a inclusão da população em espaços de poder, foram taxadas de "privilégios" e acusadas de ferir o princípio da igualdade, sobretudo pelo relator da comissão, Alceni Guerra (PFL-PR) pelo deputado Ruy Nendel (PMDB-RS). Para Alceni, "na Constituição, igualdade [é] para todos. Não se pode privilegiar nenhum segmento, seja ele racial, seja ele político, seja de credo, qualquer segmento."9

A criminalização do racismo, a proteção e promoção da cultura negra, a inclusão nos currículos escolares da história dos diferentes povos formadores do Brasil - entre eles os africanos - a titulação das terras remanescentes de quilombo e o tombamento de sítios históricos, a criação da Fundação Cultural Palmares, todos esses marcos que foram incluídos na Constituição de 1988, são indícios de que a problemática racial foi tratada, à época, no plano da cultura pelo Estado brasileiro, sem a perspectiva de reflexão sobre justiça socioeconômica. Pode-se dizer que o discurso do movimento negro transportado para a arena decisória que representou a ANC resultou em proposições antirracistas e multiculturalistas. A mudança de posição do Estado se deu na forma de políticas afins ao reconhecimento da importância e respeito à matriz africana da formação brasileira. As políticas de reconhecimento têm como principal objetivo a correção de injustiças culturais ou simbólicas, como a sujeição a padrões de interpretação e comunicação associados a uma cultura, a invisibilidade das práticas culturais de algum grupo ou o desrespeito e difamação dessas últimas Fraser (2002). Assim, pode-se dizer que apenas uma parte do core do discurso do movimento negro é agendado nesse momento.

O agendamento da política de regularização de terras quilombolas é inseparável do trabalho comunicativo e de atração de atenção das arenas decisórias feito pelo movimento negro contemporâneo. Não obstante, deve ser tratado com algumas particularidades dentro do processo de agendamento de questões de interesse desse grupo.

Como dito anteriormente, o quilombo passou a ser o principal símbolo da resistência negra no período escravocrata e, modernamente, foi retomado pelo movimento negro contemporâneo passando a ser símbolo da luta por melhores condições de vida da população negra na década de 80. O quilombo a que se referia o movimento negro contemporâneo era o quilombo de Palmares, cuja história estava minimamente documentada em livros. Pouco se sabia no que se referia à realidade e quantitativo de outros agrupamentos quilombolas.

No meio rural, a década de 80 é marcada pela intensificação das mobilizações camponesas por uma reforma agrária ampla e imediata. A proliferação dos conflitos fundiários, os efeitos da modernização da agricultura sobre a reprodução de setores do campesinato, o impacto das grandes hidrelétricas, também expulsando populações, somados aos parcos resultados da ação sindical e a um trabalho da Igreja Católica de apoio à luta por terra resultaram no aparecimento de novas vozes buscando falar pelos trabalhadores do campo e encaminhar suas demandas, como o Movimento dos Trabalhadores Rurais Sem Terra (Oliveira, 2001). Essa mobilização teve um de seus pontos 
mais altos no IV Congresso Nacional dos Trabalhadores Rurais, realizado em Brasília em 1985, ocasião em que foi lançada a proposta do I Plano de Reforma Agrária da Nova República (I PNRA). A reforma agrária estava na agenda política do Estado.

Os quilombos ou terras ocupadas coletivamente por comunidades negras não aparecem de forma explicita no I PNRA. Isso não significa que os conflitos pela ocupação e posse das terras não tocassem também as comunidades negras rurais. A chegada de grandes obras públicas, a consequente valorização das terras adjacentes, a especulação imobiliária, a ação de grileiros e o aparecimento de supostos donos de terras antes abandonadas também representam um movimento gerador de conflito e resistência nas terras ocupadas por famílias rurais de ancestralidade negra.

É possível concluir, a partir do process tracing realizado, que o movimento negro contemporâneo encampa a demanda por regularização das comunidades negras rurais. A dificuldade de manutenção das terras tradicionalmente ocupadas por comunidade negras rurais diante da expansão da fronteira agrícola, da grilagem de terras, dos grande empreendimentos e da especulação imobiliária é transportada para dentro das discussões promovidas pelo MNU pelo Centro de Cultura Negra do Maranhão (CCN) e pelo Centro de Estudo e Defesa do Negro do Pará (CEDENPA), organizações da sociedade civil que assistiam e assessoravam esses grupos em suas regiões de atuação, denunciando conflitos no campo. Nessa época, as comunidades negras rurais não possuíam uma organização política nacional própria que aglutinasse as diversas situações de disputa pela manutenção de terras ocupadas. Não obstante, se ainda não havia uma resposta nacionalmente organizada visando garantir a manutenção das comunidades negras em suas terras, é possível dizer que várias comunidades organizavam respostas locais às ameaças territoriais percebidas, bastante influenciada pela Igreja Católica (Gusmão,1990; Plínio dos Santos, 2006). A literatura disponível e os depoimentos coletados de Alberti e Pereira (2007) apontam que é no estado do Maranhão e também no Pará onde se têm as primeiras notícias de organização local para fazer frente à expulsão e expropriação de terras. Nesses estados, a luta pela manutenção dos territórios ganhará, no final dos anos 70 e início dos anos 80, o apoio das então neófitas organizações militantes do movimento negro urbano. Tanto o CCN quanto o CEDENPA estabeleceram relação de proximidade e confiança com as comunidades negras rurais que assessoravam e promoviam a articulação entre as comunidades negras locais (Arruti, 2008; Alberti; Pereira, 2007; $\mathrm{SMDH} / \mathrm{CCN}$, 2005; SMDH/CCN, 2003; Trecanni, 2006).

Em especial o $\mathrm{CCN}$ e a Sociedade Maranhanse de Direitos Humanos registraram em livros a experiência de mobilização pela manutenção das terras tradicionais na década de 80, com referências sobretudo ao quilombo de Alcântara, que teve parte de sua população deslocada em virtude da construção do Centro de Lançamento de Alcântara, construído para lançamento de engenhos aeroespaciais (SMDH/CCN, 2005; $\mathrm{SMDH} / \mathrm{CCN}, 2003) . \quad \mathrm{O} \mathrm{CCN}$ e o CEDENPA promoveram eventos de encontro e discussão com comunidades negras rurais em seus estados. Em 1986, o CCN realizou o I Encontro de comunidades negras rurais do Maranhão e em 1987, o CEDENPA promove o Encontro de Negros do Norte e Nordeste em Belém com o tema "Terra de Quilombo", conforme os relatos das lideranças Mundinha Araújo do CCN (Alberti e Pereira, 2007:247) e Zélia Amador do CEDENPA (Alberti e Pereira, 2007:249). 
O movimento negro agrega, em sua Convenção preparatória para a Constituinte realizada em 1986, em Brasília, a demanda dessas comunidades pela manutenção de seus territórios, demanda essa trazida pelas entidades do Maranhão e Pará supracitadas. A demanda pelo direto a terra desses grupos foi consenso nesse encontro e se tornou uma pauta do movimento negro a ser levada para a Assembleia Constituinte.

Vários depoimentos recolhidos por Alberti e Pereira (2007) apontam que conseguir consenso para redação das propostas a serem levadas pelo MNU não foi algo fácil, mas o caso dos grupos negros rurais sem acesso formal à terra e ameaçados por grileiros e pela expansão econômica rural do Norte e Nordeste, entrou sem dificuldade no roll de pautas que seria entregue, posteriormente, a todos os partidos e à ANC. Várias reportagens jornalísticas do acervo "Coleção Constituinte de 1988", da biblioteca do Senado Federal, noticiam esse período de definição de quais reivindicações seriam levadas à Constituinte pelo movimento negro. Nessas reportagens, o direito à regularização das terras quilombolas é citado entre as reivindicações desse grupo de interesse.

Interessa notar que nesse período pouco se conhecia acerca da dimensão do fenômeno e da realidade desses grupos. Esse pouco conhecimento histórico sobre os quilombos perdurará em todo o período de agendamento da política de regularização fundiária quilombola. Para alguns militantes do movimento negro era a primeira vez que tinham informações sobre como viviam essas comunidades. Esse é o relato de Hédio Silva Jr., presidente da Convenção e relator do documento final com as proposições do movimento negro 10:

\begin{abstract}
“(...) Eu me lembro que foi a primeira vez em que me ative a essa demanda das comunidades de quilombo (...) eu já tinha ouvido falar, mas não tinha realmente a dimensão do problema. Foi nesse encontro que especialmente o pessoal do Nordeste pautou o tema das terras de comunidades de quilombo com muito vigor e nós, então, tivemos a oportunidade de perceber a dimensão que o problema tinha."
\end{abstract}

O relato de Flávio Jorge Rodrigues da Silva, expoente do movimento negro contemporâneo em São Paulo e então membro do Fórum Estadual de Comunidades Negras de São Paulo também sugere esse pouco conhecimento em depoimento posterior ao agendamento:

\begin{abstract}
"Nós participamos dos debates que antecederam a própria vinda do artigo 68, no próprio processo constituinte, e tínhamos mais dúvidas do que certezas quanto a essa discussão. E o artigo 68 é fruto disso. Chegou um momento em que decidimos os seguinte: vamos esquecer as nossas dúvidas, vamos ver aquilo que nós temos consenso (...)"11
\end{abstract}

No campo acadêmico, Ciro Flamarion S. Cardoso (1987) apontava nos anos 80 o pouco interesse dos pesquisadores acerca do campesinato negro formado ainda no período escravista. No campo da Antropologia, que contribuirá na década de 90 e anos 2000 para a definição do quilombo enquanto grupo étnico formador da sociedade brasileira, alguns poucos trabalhos dão conta de casos de comunidades quilombos nos anos 80.

O Conselho Nacional de Desenvolvimento Científico e Tecnológico (CNPq) e o Ministério da Cultura promovem o Congresso Internacional da Escravidão, considerado o maior seminário do ano de 1988 sobre a escravidão. A situação 
das comunidades quilombolas gera alguma discussão entre antropólogos que trabalhavam com populações afro-brasileiras, a partir das discussões suscitadas pelo trabalho "Terras negras: invisibilidade desapropriada", de Maria de Lourdes Bandeira (Leite, 2002). Bandeira (1991) reconhece um ponto em comum nesses trabalhos: o apontamento da territorialidade como associada à identidade das comunidade negras rurais e como base para constituição e manutenção dessas.

Além do referido congresso, é reconhecido o pionerismo do antropólogo Alfredo Wagner Berno de Almeida na identificação e estudo das terras de uso comum. Seus trabalhos nesse tema, iniciados ainda na década de 70, trouxeram um panorama dos diferentes processos de territorialização do solo brasileiro por grupos que não necessariamente pensavam na organização territorial a partir da noção de imóvel individualizado e que regulavam seu uso com base na tradição e regras costumeiras, entre eles, as chamadas terras de preto. Uma vez em sua atuação na estrutura estatal, trabalhando no Ministério da Reforma e do Desenvolvimento Agrário (MIRAD) de 1984 a 1987, Almeida relata que no Cadastro de Glebas de terras foi criada, em 1986, a categoria "ocupações especiais", onde se incluíam as chamadas "terras de preto", "terras de santo", "terras de índio", os "fundos de pasto" e os "faxinais" dentre outros. Almeida participou da discussão dessa categoria. Estava embutida uma ideia de ocupação que levava em conta fatores identitários e culturais (Almeida, 2009). À época, nenhuma outra ação visando melhor compreender as modalidades concretas de apropriação da terra desses grupos foi tomada por parte do Estado (Almeida, 2008).

A partir dos relatos de Alberti e Pereira (2007) é possível inferir que a nascente produção antropológica sobre as comunidades negras rurais, no entanto, ainda é pouco conhecida dentro do movimento negro da época predominantemente urbano - e pelos empreendedores que atuam na ANC transportando o discurso do movimento negro.

É possível afirmar que se essa demanda não tivesse sido encampada pelo movimento negro o agendamento da regularização dessas terras não teria sido possível naquele momento. A demanda das comunidades negras rurais pelo direito às terras ocupadas segue o fluxo do processo ideológico de redefinição das relações raciais que o movimento tentava emplacar em um momento de alta visibilidade e abertura da estrutura política. De símbolo da luta negra, o quilombo passa a fazer parte da pauta de reivindicações desse movimento.

$O$ process tracing revela pistas de como essa demanda se encaixa no core do discurso transportado pelo movimento negro. A apropriação ideológica do quilombo enquanto lócus de luta contra a escravidão e como símbolo da resistência negra representa uma mudança na policy image desse fenômeno. Essa imagem será amplamente difundida pelo movimento negro contemporâneo, sobretudo no ano de centenário da Abolição. A predominância do exemplo do quilombo palmarino, que traz na história a fuga do cativeiro, a resistência por meio da luta aberta e da produção autônoma, é a ideia conhecida e transportada pelo movimento negro contemporâneo até a arena decisória, representada pela ANC. O que parece ter movido os empreendedores políticos do movimento negro dentro da ANC ao defenderem essa propositura foi um "desejo memorialístico" (Arruti, 2006) de afirmar as comunidades negras rurais como metáforas da resistência escrava e do "mundo africano entre nós" (Arruti,2006) que foram os quilombos históricos. As comunidade negras rurais passam a representar "vestígios", "restos" dos antigos quilombos, fenômeno tão caro dentro do discurso do movimento negro. Daí pode ser explicada a noção 
jurídica de "remanescentes de quilombos". Ou seja, nesse período, vigorava o entendimento de que as comunidade negras rurais representavam reminiscência de espaços do passado negro no presente, que deveriam ser protegidos e preservados. É interessante notar que a categoria "remanescentes de quilombo" está presente desde o documento resultante da Convenção do Negro pela Constituinte, em 1986 (MNU, 1986). Agendou-se uma solução de reconhecimento, com caráter de proteção da cultura negra com base em uma policy image de que as comunidade negras eram reminiscência dos antigos quilombos, símbolo da resistência racial.

Os temas afetos à igualdade racial são tratados na Subcomissão de Negros, Populações Índigenas, Pessoas Deficientes e Minorias. A policy que aqui nos interessa, a titulação das terras de quilombos, não é citada nas reuniões públicas da comissão. As referências aos quilombos nas discussões entre parlamentares e militantes são aquelas feitas ao quilombo de Palmares como símbolo da luta antirracista atual. Aparecem também referências ao movimento Quilombista de Abdias Nascimento, o quilombo sendo um modelo de sociedade que proporcionaria a democratização das relações raciais e o desenvolvimento do Brasil. Mesmo não tendo havido discussão nas reuniões públicas sobre o tema específico dos quilombos, um artigo versando sobre ele é incluído no Anteprojeto da Subcomissão que foi apresentado à Comissão de Ordem Social. Nos trabalhos da Comissão de Sistematização - que sistematizou os trabalhos das subcomissões e comissões - a proposição de titulação definitiva das terras das comunidades negras sofrerá proposituras de emendas e é possível entrever um incipiente debate sobre o tema quilombola nesse processo, também documentado por historiadores e juristas. De forma geral e também no espaço dessa Comissão, a trajetória das demandas do movimento negro na ANC indicam que a questão da regularização das terras quilombolas não foi objeto de debate acalorado (Arruti, 2006; Silva, 1997; Almeida, 2009; Trecanni, 2006; Alberti e Pereira, 2007; Pereira, 2008).

Os empreendedores políticos do movimento negro contemporâneo na ANC, assim como os militantes em geral, pouco sabiam o que representava essa demanda que se inseria dentro da pauta reivindicatória da militância negra. Em reportagem do Jornal Estado de São Paulo de dezembro de 198712, o jornal afirma que os deputados que atuaram na defesa dessa pauta não tinham estimativa acerca de quantas eram as comunidades, onde se localizavam exatamente e qual a extensão da terra que seria entregue pelo Estado aos remanescentes.

A mesma reportagem afirma que existiriam 55 lugares no Brasil que seriam, comprovadamente, remanescentes de quilombos e que algumas centenas de comunidades dependeriam de prova documental para que sua condição de remanescente de quilombo fosse atestada. É interessante notar no texto da reportagem a prevalência à época do conceito jurídico de quilombo que era vigente na Colônia e no Império, de "habitação de negros fugidos"

$\mathrm{E}$ interessante notar que em todas as versões do texto Constitucional que tramitaram na Comissão de Sistematização, a titulação das terras de quilombo sempre esteve presente, o que é mais um indicio da pouca oposição que levantava na Assembleia. Ainda no final de 1987, o jornal Estado de São Paulo noticia que dentre os acordos políticos que se teciam entre o grupo mais conservador, conhecido como Centrão, os partidos mais a esquerda e o relator 
da Comissão de Sistematização, Bernardo Cabral (PMDB-AM), estava a aprovação do direito à propriedade definitiva das terras ocupadas pelas comunidades remanescentes de quilombos 13 .

$O$ fato de ter sido inscrito no Ato das Disposições Constitucionais Transitórias, desde o primeiro ano da ANC, indica que seus empreendedores acreditavam na existência de pequeno número de comunidade remanescentes de quilombo e que, tituladas as terras dessas comunidades, o dispositivo perderia objeto (Arruti, 2006; Leite, 2000; Trecanni, 2006).

Minha hipótese, portanto, é que o movimento negro e seus empreendedores - mesmo que essa não tenha sido a intenção inicial do CCN e CEDENPA que tinha maior conhecimento dos casos de comunidades negras situaram a demanda por terra das comunidades negras dentro do core de seu discurso no polo do reconhecimento cultural. Percebo que as comunidade negras - ou remanescentes de quilombos - foram tratadas como patrimônio histórico da cultura negra, o que pedia sua preservação, tanto nas poucas falas dos empreendedores da questão racial na ANC quanto em falas comemorativas no centenário da Abolição. Não se vislumbrava, à época, o agendamento de uma política verdadeiramente fundiária, de redistribuição de terras.

As então recentes contribuições da Antropologia no que se refere às características identitárias e históricas dessas comunidades - que nem sempre coincidiam com a história de Palmares - parecem exercer pouca influência na redação do Artigo 68. Almeida (2009) também confirma que o movimento negro e seus empreendedores pouco conheciam da atualidade das comunidades que estavam chamando de "remanescentes de quilombo". A partir da leitura do material pesquisado e do depoimento desse autor, que acompanhou a tramitação desse artigo na ANC, é possível inferir que a defesa desse dispositivo foi feita a partir da imagem heróica e idílica do quilombo de Palmares.

Prevaleceu entre os militantes do movimento do movimento negro, que era predominantemente urbano e gestado nas grandes capitais, o pouco conhecimento sobre a situação das comunidades negras rurais (Alberti e Pereira, 2006; Arruti, 2006; Silva, 1997). Esses fatores, somados à afinidade da matéria com o campo da cultura - com a consequente ausência de qualquer discussão que adentrasse uma reforma da estrutura fundiária - explicam os poucos pontos de vetos ao que esse tema esteve sujeito. Não foi possível entrever nenhuma disputa entre coalizões de defesa opostas no que se refere à redação do Artigo 68, situação bastante diferente do que ocorrerá no período de sua regulamentação, nos anos 90 e 2000.

Os inputs ideológicos promovidos pelo movimento negro que geraram um abalo do monopólio político que o paradigma da democracia racial representava, a grande visibilidade que o tema racial ganha entre 1987 e 1988, a forma descentralizada de funcionamento da ANC - sem um texto base e permitindo que toda demanda social fosse trazidas às Subcomissões - o relativo consenso que as pautas do campo do reconhecimento cultural obtiveram na Constituinte e na esfera do discurso comunicativo como um todo são os fatores que explicam as mudanças institucionais conquistadas pelo movimento negro nessa época, entre elas o agendamento do artigo 68 do ADCT.

Uma leitura simples do cenário atual da política de regularização fundiária, hoje operada pelo Instituto Nacional de Colonização e Reforma Agrária, mostra que o dispositivo previsto no Artigo 68 do ADCT teve efeitos 
não esperados no mundo da politcs e das policy. O Artigo 68 ADCT é inscrito no texto constitucional como uma política de reconhecimento cultural, no entanto, o texto permite que ele dê origem a uma política com foco na redistribuição de terras no Brasil e não somente focada no reconhecimento cultural de sua existência histórica desses grupos. As poucas discussões dentro do movimento negro na mídia e na ANC não davam a dimensão de que, nos anos 90, o Artigo 68 do ADCT se tornaria um instrumento de luta pelo reconhecimento de direitos territoriais apropriado por várias comunidades rurais e também urbanas.

A relativa tranquilidade com que é feita a inserção do Artigo 68 na $\mathrm{CF}$ 1988 contrasta com o período de regulamentação desse dispositivo, marcado por intensas disputas ideológicas sobre o conceito de "remanescentes de quilombo" (quem são, afinal, os quilombolas?) e "terras ocupadas" e pela formação de coalizões de defesa que envolverão uma miríade de atores, muitos não tendo participado do processo de agendamento do Artigo 68. Ou seja, a redação do Artigo 68 não significou acatamento imediato das demandas por terras. Nos dias atuais, resta concluir que o dispositivo gerou um efeito não esperado no campo da política fundiária.

A promulgação da Constituição é seguida de um movimento de grupos de camponeses negros que passam a adotar a identidade de "remanescentes de quilombo" na interlocução com a burocracia estatal. Surge, também nos anos 90, a Coordenação de Articulação das Comunidades Negras Rurais Quilombolas (CONAQ), gestada dentro do movimento negro. Interessa lembrar, como resultado da redação do Artigo 68 do ADCT, que, por meio da alocação de recursos políticos e/ou monetários, uma determinada política pública pode oferecer ensejo para a criação e/ou consolidação de grupos de interesses. Ou seja, as políticas públicas como instituições que são, estabelecem regras do jogo e moldam os grupos de interesse em torno dela (Pierson, 2006). Esse parece ser também o resultado do surgimento do Artigo 68, que institui uma nova categoria jurídica, os "remanescentes de quilombos" e mobiliza grupos negros rurais a se organizarem em torno dessa nova categoria de direitos. A formação desse grupo de interesse - a CONAQ - bem como o apoio de uma coalização de defesa dessas comunidade criará constrangimentos para a manutenção do Artigo 68 no texto Constitucional diante das tentativas de supressão nos anos 90, bem como contra definições muitos restritivas de "remanescentes de quilombos".

Para os cientistas políticos que examinam políticas públicas como instituições é um pressuposto analítico o de que as políticas públicas estruturaram os processos políticos subsequentes. Ou seja, a política cria as políticas públicas e estas, por sua vez, modificam a política. Assim, as políticas públicas devem ser observadas tanto como o objeto final, quanto como o objeto inicial de análise (Skocpol, 1995). O presente trabalho visou oferecer uma compreensão do processo discursivo encaminhado pelo movimento negro e dos fatores contextuais que, juntos, possibilitaram a ruptura que o dispositivo do Artigo 68 representa. Assim, a pesquisa representa uma análise do agendamento de uma política pública como objeto final a ser entregue a uma população. No entanto, como vários dispositivos inseridos na Constituição de 1988, trata-se de um agendamento incompleto, que se arrasta até os anos 2000, com grande dificuldades em se estabelecer um novo ponto de equilíbrio. 
ABREU, Alzira Alves (org). Dicionário Histórico Biográfico Brasileiro - Pós 1930. Volume I. Rio de Janeiro, FGV-CPDOC, 2001.

ALBERTI, Verena.; PEREIRA, Amilcar Araújo. Histórias do movimento negro no Brasil: depoimentos ao CPDOC. Rio de Janeiro, Pallas/CPDOC-FGV, 2007.

ALMADA, Sandra. Abdias Nascimento: Retratos do Brasil Negro. [S.l.], Selo Negro - Grupo Summus, 2009.

ALMEIDA, Alfredo Wagner Berno. "Quilombos: Repertório Bibliográfico de uma Questão Redefinida (1995-1997)”. BIB, Rio de Janeiro, n. 45, 1998, p. 5170.

ALMEIDA, Alfredo Wagner Berno. "Entrevista: ALFREDO WAGNER BERNO DE ALMEIDA a Guilherme Mansur Dias”. Ruris, Campinas, vol. 3, n. 2. 2009, p.17-54

ARRUTI, José Mauricio. Mocambo: antropologia e história do processo de formação quilombola. Bauru/São Paulo, Edusc, 2006

ARRUTI, José Mauricio. "Quilombos”. In: PINHO, O. (Org). Raça: Perspectivas Antropológicas. Salvador, ABA /Ed. Unicamp/EDUFBA, 2008

BANDEIRA, M.L. “Terras negras: invisibilidade expropriadora”. In: LEITE, I.B.(Org.). Terras e territórios negros no Brasil - Textos e Debates. Florianópolis, NUER- UFSC, Ano I, n. 2, 1991, p. 7-24

BASTIDE, Roger; FERNANDES, Florestan. Brancos e Negros em São Paulo. São Paulo, Companhia Editora Nacional, 1959.

BARCELLOS, D. M. de et al. Comunidade negra de Morro Alto: historicidade, identidade e territorialidade. Porto Alegre, Ed. UFRGS, 2004.

BAUMGARTNER, Frank R., JONES, Bryan D. Agenda and instability in American politics. Chicago, The University of Chicago Press, 2009

BÉLAND, D., COX, R.H. "Ideas and Politics". In: BÉLAND, D., COX, R.H.(Orgs). Ideas and Politics in Social Science Research. New York, Oxford University Press, 2011

BLYTH, Mark. "The transformation of the Swedish model: economic ideas, distributional conflict and institutional change". World Politics, v. 54, p.1-26, October, 2001.

CARDOSO, Ciro Flamarion Santana. Escravo ou camponês? $O$ protocampesinato negro nas Américas. São Paulo, Brasiliense, 1987.

CARDOSO, Fernando Henrique. Capitalismo e Escravidão no Brasil Meridional. Difusão Européia, São Paulo, 1962.

COUTO, C. G; ARANTES, R. B. "Constituição ou políticas públicas? Uma avaliação dos anos FHC”. In: ABRUCIO, F. L; LOUREIRO, M. R. G. (orgs.). $O$ 
Estado numa era de reformas: os anos FHC - Parte 1. Brasília: MP/SEGES, 2002, p. 75-120.

DOMINGUES, P. "Movimento negro brasileiro: alguns apontamentos históricos”. Tempo, Rio de Janeiro, vol.12, n.23, 2007, p. 100-122.

FRASER, N. "Da redistribuição ao reconhecimento? Dilemas da justiça da era pós-socialista”. In: SOUZA, J. (Org.) Democracia hoje novos desafios para a teoria democrática contemporânea. Brasília, Editora Universidade de Brasília, 2001,p.245-282.

FREYRE, Gilberto. Casa-grande e Senzala. Rio de Janeiro, Record, 1992.

GUIMARÃES. A.S.A. "Racismo e anti-racismo no Brasil”. Novos Estudos, n.43, 1995, p. 26-44.

GUSMÃO, N.M.M. A dimensão política da cultura negra no campo: uma luta, muitas lutas. Tese de Doutorado, Antropologia Social, USP, 1990.

IANNI, Otavio. As Metamorfoses do Escravo. Difusão Européia do Livro, São Paulo, 1962.

JONES, B. D.; BAUMGARTNER, F. R. "From There to Here: Punctuated Equilibrium to the General Punctuation Thesis to a Theory of Government Information Processing”. The Policy Studies Journal, vol. 40, No. 1, 2012, p.120.

LEITE, I.B. "Os Quilombos no Brasil: Questões Conceituais e Normativas". Etnográfica, vol. IV, n. 2, 2000, pp. 333-354.

LEITE, Ilka Boaventura. Legado do testamento: A comunidade de casca em perícia. Florianópolis, Nuer, 2002.

MAGGIE, Y. "Cor, hierarquia e sistema de classificação". Estudos Históricos, Rio de Janeiro, vol 7, n.14, 1994, p.149-160.

MAIO, M.C. O "Projeto UNESCO e a agenda das Ciências Sociais no Brasil dos anos 40 e 50". RBCS, nol. 14, n. 41, p. pp. 141-158, outubro de 1999.

MNU. 1978 - 1988: 10 anos de luta contra o racismo. São Paulo, Confraria do Livro, 1998.

MNU. Documento contendo as reivindicações da Convenção Nacional do Negro pela Constituição [online]. Brasília, 1986. Disponível em <http://www.institutobuzios.org.br/>. Acesso em: 24 de março de 2014.

NASCIMENTO, A. "O quilombismo: uma alternativa política afro-brasileira". AFRODIÁSPORA - Revista de estudos do mundo negro. Rio de Janeiro, IPEAFRO, v. 6-7,1985.

NASCIMENTO, A. "Quilombismo: an afro-brazilian political alternative". Journal of Black Studies, v. 11, Issue 2, 1980, p. 141-178. 
OLIVEIRA, A.U. "A longa marcha do campesinato brasileiro: movimentos sociais, conflitos e Reforma Agrária”. Estudos Avançados, São Paulo, v.15, n.43, 2001, pp. 185-206.

PEREIRA, A.A. "Influências externas, circulação de referenciais e a constituição do movimento negro contemporâneo no Brasil: idas e vindas no "Atlântico Negro”. Ciênci. Let, Porto Alegre, n.44, 2008, pp. 215-236.

PEREIRA, A.A. 'O mundo negro': a constituição do movimento negro contemporâneo no Brasil (1970-1995). Tese de Doutorado, História, Niterói, UFF, 2010.

PIERSON, P. "Public Policies as Institutions". In: SHAPIRO, I.; SKOWRNEK, S.; GALVIN, D. (orgs). Rethinking Political Institutions. New York, New York University Press, 2006, p. 114-131.

PLÍNIO DOS SANTOS, C.A.B. Quilombo Tapuio (PI): terra de memória e identidade. Dissertação de Mestrado, Antropologia Social, Brasília, UnB, 2006.

SCHERER-WARREN, I. "Das mobilizações às redes de movimentos sociais". Soc. Estado, Brasília, vol.21, n.1, 2006, p. 109-130.

SCHMIDT, V. "Discursive Institutionalism: The Explanatory Power of Ideas and Discourse”. Annual Review of Political Science, Vol. 11, 2008, p. 303-326.

SKOCPOL, T. Protecting Soldiers and Mothers. The Political Origins of Social Policy in the United States. Harvard University Press, 1995.

SILVA, D. S. "Apontamentos para compreender a criação e regulamentação do Artigo 68 do ato das Disposições Constitucionais Transitórias de 1988". Boletim Informativo NUER. Florianópolis, NUER/ Fundação Cultural Palmares - v. 1, n. 1, 1997, p.9-47.

SOCIEDADE MARANHENSE DE DIREITOS HUMANOS (SMDH) e CENTRO DE CULTURA NEGRA (CCN). Terras de preto no Maranhão: quebrando o mito do isolamento. Coleção Negro Cosme, Vol. III, São Luís: SMDH/CCNMA/PVN, 2002.

SMDH/CCN. Projeto Vida de Negro: 15 anos de luta e fortalecimento dos territórios quilombolas. São Luís, SMDH/CCN-MA/PVN, 2003.

ROCHA, E. G. T. "O Decreto 4887 e a regulamentação das terras dos remanescentes das comunidades dos quilombos". Boletim Informativo do Nuer: Territórios quilombolas: reconhecimento e titulação das terras. Florianópolis, v. 2, n. 2, 2005, p. 97-102.

TRECANNI, G.D. Terras de quilombo: caminhos e entraves do processo de titulação. Belém, Secretaria Executiva de Justiça/Programa Raízes, 2006.

Recebido em 10/11/2016. Aprovado em 30/12/2016. 